Original Article

\title{
Comparison of temporal changes in trunk flexion angle and gluteal pressure during continuous sitting
}

\author{
Min-HeE KIM ${ }^{1)}$, Won-GYU Yoo ${ }^{1 *}$ \\ 1) Department of Physical Therapy, College of Biomedical Science and Engineering, Inje University: \\ 607 Obangdong, Gimhae, Gyeongsangnam-do 621-749, Republic of Korea
}

\begin{abstract}
Purpose] This study investigated temporal changes in trunk flexion angle and gluteal pressure during computer work with continuous sitting. [Subjects and Methods] This study involved 10 males subjects aged 21-29 years. During 30 min of data collection with a Tekscan system and a video camera, peak gluteal pressure and changes in trunk flexion angle were analyzed with the COMFOM at research 6.20 and Pro-Trainer 10.1 programs, respectively, at 10,20, and $30 \mathrm{~min}$. [Results] The result showed no significant change in gluteal pressure after 10, 20 , or $30 \mathrm{~min}$. However, changes in trunk flexion angle increased significantly after $10 \mathrm{~min}<20 \mathrm{~min}<30 \mathrm{~min}$. [Conclusion] Trunk flexion is necessary for repositioning, unless one can maintain a posture for a long time without movement. Future research should analyze repositioning methods according to individual characteristics. Key words: Gluteal pressure, Repositioning, VDT worker
\end{abstract}

(This article was submitted Mar. 4, 2017, and was accepted Apr. 17, 2017)

\section{INTRODUCTION}

Prolonged sitting in combination with poor workstation ergonomics have been implicated in the development of musculoskeletal problems during visual display terminal (VDT) work ${ }^{1)}$. In a typical VDT work day, a fixed position is maintained over a long period of time ${ }^{2}$. Localized pressure at the skin surface is believed to cause blockage of capillary blood flow and subsequent ischemic damage ${ }^{3)}$. Localized pressure is more easily relieved by repositioning or by pressure-relieving supports, although with the latter, there is less freedom to move and the body weight is concentrated in the ischial area ${ }^{3)}$. Repositioning is a key component of skin care, because repositioning can be pressure relieving or pressure reducing. Thus, in this study, we investigated temporal changes in trunk flexion angle and gluteal pressure during computer work with continuous sitting.

\section{SUBJECTS AND METHODS}

This study was performed on 10 males subjects, aged 21-29 years (mean age=25.0 \pm 4.8 years) and whose height and weight were $174.2 \pm 2.5 \mathrm{~cm}$ and $66.4 \pm 4.3 \mathrm{~kg}$, respectively. Subjects with conditions that might affect trunk mobility, such as injury or neurological deficits in the hip or lower extremities during the previous year, were excluded. The purpose and methods of the study were explained to the participants before their inclusion in the study. They provided informed consent according to the principles of the Declaration of Helsinki.

During 30 min of data collection with a Tekscan system and a video camera, peak gluteal pressure and changes in trunk flexion angles were analyzed using the COMFOMat research 6.20 and Pro-Trainer 10.1 programs, respectively, at 10, 20, and $30 \mathrm{~min}$. A single-blinded recording method was used to ensure that results were not affected by the participant's intentional bias. The SPSS software (ver. 14.0; SPSS, Chicago, IL, USA) was used to analyze significant differences in changes in

*Corresponding author. Won-gyu Yoo (E-mail: won7y@inje.ac.kr)

(C2017 The Society of Physical Therapy Science. Published by IPEC Inc.

This is an open-access article distributed under the terms of the Creative Commons Attribution Non-Commercial No Derivatives (by-nc-nd) License. (CC-BY-NC-ND 4.0: https://creativecommons.org/licenses/by-nc-nd/4.0/) 
trunk flexion angle and gluteal pressure during continuous sitting. Statistically significant differences were assessed using a repeated-measures one-way ANOVA, with the level of statistical significance set at $\mathrm{p}<0.05$.

\section{RESULTS}

There was no significant change in gluteal pressure after 10,20 , or $30 \mathrm{~min}(0.68 \pm 0.28,0.67 \pm 0.27$, and $0.67 \pm 0.29 \mathrm{~kg} /$ $\mathrm{cm}^{2}$, respectively). However, changes in the trunk flexion angle increased significantly after $10 \min \left(2.5 \pm 1.8^{\circ}\right)<20 \mathrm{~min}(3.8$ $\left.\pm 2.4^{\circ}\right)<30 \min \left(5.2 \pm 2.6^{\circ}\right)$.

\section{DISCUSSION}

Maintaining an upright sitting posture is an important factor for preventing and reducing posture-related low-back pain, which is well recognized by the general public as well as clinicians ${ }^{1)}$. Theoretically, a flexed-relaxed posture results in a higher load at the spine and lower muscle activation of the trunk versus upright sitting, which may lead to excessive stress on passive structures, such as ligaments and discs, and thus acts a risk factor for low-back pain ${ }^{1,4)}$. However, according to research results, movement of the trunk is a major reason for displacement of position. Natural bending and stretching of the trunk while in the sitting position is necessary. With increased time working at a computer, the flexion angle of the trunk does increase, but this does not change the average peak pressure on the buttocks significantly. Continuous movement of the trunk causes repositioning and seems to prevent an increase in pressure. Maintaining a motionless position for a long time may increase pressure on the buttocks, even though the position is 'ideal.' Thus, a comfortable chair with cushioning and a backrest carries the risk of increasing pressure on the buttocks, because it can decrease movement of the trunk and induce a motionless position for a long time ${ }^{4,5)}$. Unlike in patients, various backrests and cushions may increase the pressure on the buttocks of a healthy adult; therefore, sitting away from a backrest is a good position in that it allows movement of the trunk when changing position ${ }^{5)}$. Many researchers have reported that bending the trunk during work at a computer is disadvantageous $^{1,2)}$. However, some trunk flexion is necessary for repositioning, unless one can maintain a posture for a long time without movement. Future research should analyze repositioning methods according to individual characteristics.

\section{ACKNOWLEDGEMENT}

This work was supported by the 2016 Post-doctoral Research Program of Inje University.

\section{REFERENCES}

1) Marcus M, Gerr F, Monteilh C, et al.: A prospective study of computer users: II. Postural risk factors for musculoskeletal symptoms and disorders. Am J Ind Med, 2002, 41: 236-249. [Medline] [CrossRef]

2) Straker L, Duncan P: Psychophysical and psychosocial comparison of squat and stoop lifting by young females. Aust J Physiother, 2000, 46: 27-32. [Medline] [CrossRef]

3) Theaker C, Mannan M, Ives N, et al.: Risk factors for pressure sores in the critically ill. Anaesthesia, 2000, 55: 221-224. [Medline] [CrossRef]

4) Carcone SM, Keir PJ: Effects of backrest design on biomechanics and comfort during seated work. Appl Ergon, 2007, 38: 755-764. [Medline] [CrossRef]

5) Driessen MT, Proper KI, van Tulder MW, et al.: The effectiveness of physical and organisational ergonomic interventions on low back pain and neck pain: a systematic review. Occup Environ Med, 2010, 67: 277-285. [Medline] [CrossRef] 